\title{
Optimal Service Commission Contract Design of OTA to Create 020 Model by Cooperation with TTA under Asymmetric Information
}

\author{
Pingping Shi, ${ }^{1}$ Yaogang $\mathrm{Hu}\left(\mathbb{D},{ }^{2}\right.$ and Yongfeng Wang ${ }^{1}$ \\ ${ }^{1}$ School of Management, Chongqing University of Technology, Chongqing 400054, China \\ ${ }^{2}$ School of Electrical and Electronic Engineering, Chongqing University of Technology, Chongqing 400054, China \\ Correspondence should be addressed to Yaogang Hu; 569934301@qq.com
}

Received 16 March 2021; Revised 19 April 2021; Accepted 21 April 2021; Published 3 May 2021

Academic Editor: Ming Bao Cheng

Copyright (c) 2021 Pingping Shi et al. This is an open access article distributed under the Creative Commons Attribution License, which permits unrestricted use, distribution, and reproduction in any medium, provided the original work is properly cited.

\begin{abstract}
This paper studies the service commission contract of an online travel agency (OTA) to integrate the online to offline (O2O) model by cooperation with a traditional travel agency (TTA) under asymmetric information. The principal-agent models are established with symmetric and asymmetric service information, respectively. Further, the impacts of asymmetry information on the revenue of the OTA, TTA, and the whole O2O model and the properties of optimal commission contract are analyzed. The paper notes management implications: (1) OTA designs service commission contracts by weighing the fixed payment and service commission coefficient for different incentives to TTAs with different serviceabilities and (2) because the existence of asymmetric information always leads to the damage of OTA's expected revenue, OTA should encourage the TTA to disclose private service information.
\end{abstract}

\section{Introduction}

With the rapid development of Internet and information technology, it is a popular and convenient way for tourists to buy more diverse tourism products and services through online travel agencies (OTAs) [1-3]. However, online tourism product homogenization makes OTAs reduce the service quality to attract more tourists, such as cashback and low price, forcing consumption in the experience, which seriously increase tourists' complaints and hinder the healthy development of online tourism [4-6]. To improve competitive advantage and realize differentiation, some OTAs (e.g., Ctrip) open up offline stores to achieve online to offline $(\mathrm{O} 2 \mathrm{O})$ model for providing personal information and advice to tourists, and some cooperate with traditional travel agencies (TTAs), such as Uzai (http:// www.uzai.com/) and ZhongXin TTA, Lvmama (http:// www.lvmama.com), and JinJiang TTA [4]. In the process of cooperation between OTAs and TTAs, it is difficult for OTAs to observe TTAs' service information, which makes the cooperation and incentive problem more complicated.
Therefore, how to design the commission contract of TTAs strategically for OTAs is an urgent problem to implement $\mathrm{O} 2 \mathrm{O}$ strategy.

The $\mathrm{O} 2 \mathrm{O}$ model, as a new e-commerce business model, combines online trading and offline experience and has become an important strategy for the development of enterprises in recent years [7]. With the rapid development of OTAs, the online channel plays a crucial role in tourism and hospitality, and the tourism $\mathrm{O} 2 \mathrm{O}$ model achieved by the cooperation between OTAs and hotels or airlines is a common phenomenon. Therefore, there is a growing popularity on the cooperation problem between OTAs and hotels or airlines and they have gotten some effective cooperation strategies $[1,8-11]$. However, to seek better business opportunities, OTAs have to attach importance to the offline service to achieve differentiation. Although some scientific researchers have demonstrated the importance of TTAs' advice-offering and OTAs' attributes in travelers' booking, little literature in the hospitality and tourism fields has studied the service contract problem of cooperation between OTAs and TTAs. 
To fill this gap and provide some suggestions for OTAs and TTAs managers on establishing the $\mathrm{O} 2 \mathrm{O}$ model through service cooperation, this paper proposes a cooperation model to describe decision interactions of an OTA and a TTA. The OTA and TTA play a principal-agent model in which the OTA, as the principal player, determines the service commission and the TTA, as the agent, determines service effort. In addition, in the $\mathrm{O} 2 \mathrm{O}$ model, because the OTA and TTA are relatively independent, TTA's private information is difficult to disclose and it often hides its own service information to obtain higher revenue. By comparing the case of information symmetry and asymmetry, the impacts of asymmetry information on OTA's service contract, TTA's information value, and the revenue of OTA and TTA are analyzed.

The rest of this paper is organized as follows. Section 2 reviews the related literature. Section 3 describes the service cooperation between an OTA and a TTA. Section 4 analyzes and compares equilibriums of symmetric and asymmetric information and further analyzes equilibriums when TTA's ability is continuous. Section 5 presents the results of numerical analyses. Section 6 concludes this paper by summarizing some of the managerial implications obtained.

\section{Literature Review}

According to the purpose of studying the service cooperation contract design of OTAs and TTAs, this section reviews three distinct of literature studies about the $\mathrm{O} 2 \mathrm{O}$ model, service cooperation, and cooperation between tourism enterprises and OTAs.

2.1. O2O Model. Since Alex Rampel put forward the concept of the $\mathrm{O} 2 \mathrm{O}$ model, it has attracted wide attention in academia. Although the concept and classification of the $\mathrm{O} 2 \mathrm{O}$ model are different because of the scholars' different research perspectives, it is a business model for the effective integration of online and offline stores [4, 7]. It is believed that $\mathrm{O} 2 \mathrm{O}$ is a new business model, which can disclose product information, change consumer brand awareness, and mitigate the adverse effects of product uncertainty on consumers' shopping decisions [12]. By using 311 respondent data from $\mathrm{O} 2 \mathrm{O}$ e-commerce users in Greater Jakarta Area, Savila et al. showed that both multichannel integration and trust have a significant effect on both customer online loyalty and customer offline loyalty that drive customer repurchase intention [13].

According to the existing research about the $\mathrm{O} 2 \mathrm{O}$ model, it can be divided into two categories: one is to purchase online and then experience offline, which can also be called online to offline; the other is to experience offline and then purchase online, which can also be called offline to online [14]. In the hospitality and tourism industry, because tourists have to experience tourism products offline, the $\mathrm{O} 2 \mathrm{O}$ model achieved by the cooperation between OTAs and hotels or airlines is a common phenomenon. From the perspective of the supply chain, scholars more emphasize the sale cooperation between the OTAs and hotels or airlines and have gotten some effective cooperation strategies $[1,8-11]$. In the retail industry, as the major characteristic feature of a product is tangible, it can be touched and tried out. The $\mathrm{O} 2 \mathrm{O}$ model, achieved by cooperating with others or opening by oneself $[14,15]$, becomes the main research direction. Considering that the service cost and effort information of the showroom are asymmetry, Jin et al. study the design of the commission contract of offline to online, which is considered that the showroom and online retailer have impacts on consumers' purchasing decisions, respectively [15]. In practice, online sale efforts and offline services will affect the demand for each other. Therefore, it is difficult to highlight the integrity of the online retailer and store cocreating $\mathrm{O} 2 \mathrm{O}$ model by splitting online and offline demand.

Despite the impact of technology and the advent of online bookings, offline channels play a pivotal role in the tourism supply chain. Unlike the general retail product, the tourism product of a travel agency cannot be touched, transported, stored, or returned. The functions of offline channels are different between general retailer and travel agency. The offline channels of general retailer provide touching, trying, and even online return service for consumers. The offline channels of travel agency provide scene experience, personal and professional information, and advice to meet travelers' demands on a continuous basis by gathering and organizing information $[16,17]$. The $\mathrm{O} 2 \mathrm{O}$ model of travel agency in this paper is an integration of online and offline. Both online sale efforts and offline services will have an impact on the overall demand for the $\mathrm{O} 2 \mathrm{O}$ model.

2.2. Service Cooperation. The existing literature on service cooperation is mostly concentrated in the supply chain field. Service cooperation not only reduces the competition between direct and retail channels but also improves supply chain revenue [18-21]. Unit service reward and service cost sharing are the main forms of service cooperation. To avoid channel conflict and improve service efficiency, Xiao, Dan, and Zhang studied after-sale service cooperation between direct channel and retailers in which direct channel pays unit service commission to retailers [18]. In the $\mathrm{O} 2 \mathrm{O}$ retail market, the service cost sharing mechanism is introduced to coordinate conflicts and achieve a win-win strategy, thereby improving the performance of the entire $\mathrm{O} 2 \mathrm{O}$ supply chain [19]. Due to the importance of presales services in purchasing decisions, Zhou et al. introduce that the service cost sharing contract can effectively stimulate the retailer to improve his service level while free riding occurred [20]. Considering that the retailer provides the same service level in both channels or not, Yang and Zhang compare the manufacturer's optimal profit and retailer's optimal profit under the condition of different services and the same service and provide differentiated services to enable the system to achieve the optimal profit [21]. However, the completely symmetrical assumptions in the above literature are not currently common practice. The adverse selection and moral hazard are always in the cooperation process [22]. 
2.3. Cooperation between Tourism Enterprises and OTAs. Clearly, the OTAs are an extremely important part of the tourism supply chain, recognized as an online distribution channel for hotels and airlines. A larger number of scholars have emerged to pay attention to the issue of the cooperation problem between hotels, airlines, and OTAs, such as pricing strategy, cooperation form, and coordination strategy $[1,8-11]$. Koo et al. point out that the airlines are less likely to use OTA platforms if the airlines have a large loyal consumer base or if the OTA platform is highly competitive [8]. Ling et al. and Guo et al. study the optimal pricing strategy for tourism hotels when they operate their online channel by cooperation with an OTA $[1,9]$. Considering the overbooking of hotels, Dong and Ling study the pricing and overbooking strategies of a hotel in the context of cooperation with multiple OTAs and analyze how these strategies influence the cooperation process [10]. The commonly used "first come first serve" form puts hotels in a disadvantageous position especially when the OTAs have much more market attractiveness than the hotels. Xu et al. propose a new form named "setting Online-Exclusive-Rooms" for a hotel to collaborate with a third-party website on room booking service [11].

To get a new business opportunity, the TTAs are increasingly aware of the need to open up online markets' cooperation with OTAs because of the low volume of visits and lack of e-commence operating experience of self-built website $[3,4]$. Therefore, a few scholars have provided suggestions on the cooperation between TTA and OTA. Based on the resource-based view, Shi and Long analyze the complementary resources input decisions of OTAs and TTAs cocreating the $\mathrm{O} 2 \mathrm{O}$ model, which do not propose a clear form of cooperation [3]. In a supplemental study, Long and Shi study the optimal pricing strategies of a tour operator and an OTA when they achieve the $\mathrm{O} 2 \mathrm{O}$ business model through online sale and offline service cooperation to develop the advantage of complementary resources [4].

However, no study has addressed the problem of an OTA that wants to achieve its $\mathrm{O} 2 \mathrm{O}$ model by cooperating with a TTA with private information. In this situation, the OTA has little information and experience regarding offline service and knows little about how to design a service contract to disclosure TTA's real information. To enrich the scientific literature and provide some suggestions to OTA on how to pursue offline service, this paper studies the optimal service contract of OTAs under asymmetric information through the analysis of a simple $\mathrm{O} 2 \mathrm{O}$ model composed of an OTA and a TTA.

\section{Problem Description and Assumptions}

In this paper, the $\mathrm{O} 2 \mathrm{O}$ model, combining both trading and offline service, achieved by service cooperation of an OTA and a TTA is considered herein. Table 1 summarizes the main notation and its definitions used in this paper.

The OTA makes some effort to induce customers to make reservations through its website, such as ranking position. According to the literature [1], $c\left(e_{O}\right)$ is a convex increasing function with $\mathrm{d} c\left(e_{O}\right) / \mathrm{d} e_{O}>0, \mathrm{~d}^{2} c\left(e_{T}\right) / \mathrm{d} e_{T}^{2}>0$, and $c\left(e_{O}\right)=0$. The sale cost of OTA is $c\left(e_{O}\right)=\eta_{O} e_{O}^{2} / 2$, where $\eta_{O}$ is the OTA's sale cost coefficient, which is widely used in the cost management literature [23-26].

While the TTA provides offline services for tourism products, such as the scene experience and personalized and professional travel advice, the service effort is the cost of hiring salespersons by TTA. According to the literature $[4,25,26]$, a strictly convex service function $c\left(e_{T}\right)$ is used to depict TTA's unit cost of service effort, $c\left(e_{T}\right)=\eta_{T} e_{T}^{2} / 2$, where $\eta_{T}$ is the TTA's service cost coefficient, $\mathrm{d} c\left(e_{T}\right) / \mathrm{d} e_{T}>0$, and $\mathrm{d}^{2} c\left(e_{T}\right) / \mathrm{d} e_{T}^{2}>0$.

The demand for $\mathrm{O} 2 \mathrm{O}$ model $q$ is influenced by OTA's saleability $s_{O}$, sale effort $e_{O}$, TTA's serviceability $s_{T}$, service effort $e_{T}$, market scale $\theta$, and market random factors $\xi$.

$$
q=f\left(s_{O}, e_{O}\right)+g\left(s_{T}, e_{T}\right)+u(\theta)+\xi
$$

where $f_{s_{O}}>0, f_{s_{O}} s_{O} \leq 0, f_{e_{O}}>0, f_{e_{O}, e_{O}} \leq 0, g_{s_{T}}>0, g_{s_{T} s_{T}} \leq 0$, $g_{e_{T}}>0, g_{e_{T} e_{T}} \leq 0, u_{\theta}>0, u_{\theta \theta} \leq 0$, and $\xi$ follows a normal distribution $\xi \in N\left(0, \sigma^{2}\right)$.

In this paper, according to the literature [27], let $f\left(e_{O}\right)=$ $s_{O} e_{O}, g\left(e_{T}\right)=s_{T} e_{T}$, and $u(\theta)=\theta$. Thus, the demand for $\mathrm{O} 2 \mathrm{O}$ model is $q=s_{O} e_{O}+s_{T} e_{T}+\theta+\xi$. Assuming that the revenue of $\mathrm{O} 2 \mathrm{O}$ model is proportional to its demand, the revenue of $\mathrm{O} 2 \mathrm{O}$ model can be simplified into $\Pi(q)=s_{O} e_{O^{+}}$ $s_{T} e_{T}+\theta+\xi$. Following the studies of Jin et al. [15] and He et al. [28], OTA provides service commission $(a, b)$ to motivate TTA to make service effort, where $a$ represents fixed payment and $b$ denotes service commission coefficient or the rate of revenue sharing. Therefore, given $(a, b)$, the service commission that OTA pays for TTA is $T(q)=a+b \Pi(q)$.

Based on the above assumptions, the OTA's revenue function is obtained as follows:

$$
\begin{aligned}
\Pi_{O}= & \Pi(q)-T(q)-c\left(e_{O}\right)=(1-b)\left(s_{O} e_{O}+s_{T} e_{T}+\theta+\xi\right) \\
& -a-\frac{\eta_{O} e_{O}^{2}}{2} .
\end{aligned}
$$

Assuming that OTA is risk-neutral and its utility is equal to expected revenue, the OTA's expected revenue is

$$
E \Pi_{O}=(1-b)\left(s_{O} e_{O}+s_{T} e_{T}+\theta\right)-a-\frac{\eta_{O} e_{O}^{2}}{2} .
$$

The TTA's revenue is

$$
\Pi_{T}=T(q)-c\left(e_{T}\right)=a+b\left(s_{O} e_{O}+s_{T} e_{T}+\theta+\xi\right)-\frac{\eta_{T} e_{T}^{2}}{2} .
$$

Assuming that TTA is risk-neutral risk aversion, one form of the utility function dominant in both theoretical and applied work in areas of decision theory and finance is the exponential utility function. Following the literature [29], $U_{T}\left(\Pi_{T}\right)=-e^{-r \Pi_{T}}$, where $r$ denotes TTA's risk aversion coefficient and $r>0, r=0$, and $r<0$ are risk aversion, risk neutrality, and risk preference, respectively. By certainty equivalence method, the revenue of TTA is obtained as follows: 
TABle 1: Notation and definitions.

\begin{tabular}{lc}
\hline Notation & Definitions \\
\hline$s_{O}$ & Sale ability of OTA \\
$e_{O}$ & Sale effort of OTA \\
$C\left(e_{O}\right)$ & Sale cost of OTA \\
$\eta_{O}$ & Sale cost coefficient of OTA \\
$s_{T}$ & Serviceability of TTA \\
$e_{T}$ & Service effort of TTA \\
$\eta_{T}\left(e_{T}\right)$ & Service cost coefficient of TTA \\
$Q$ & Unit cost of service effort of TTA \\
$\theta$ & The demand for O2O model \\
$\xi$ & Market scale \\
$T(q)$ & Market random factors \\
$A$ & Service commission that OTA pays for TTA \\
$B$ & Fixed payment \\
$\Pi(q), \Pi_{O}, \Pi_{T}$ & The revenue of O2O model, OTA, and TTA, respectively \\
$E \Pi_{O}, E \Pi_{T}$ & The expected revenue of OTA and TTA, respectively \\
$U_{T}\left(E \Pi_{T}\right)$ & The utility function of TTA \\
$R$ & TTA's risk aversion coefficient \\
$I$ & The state of TTA's serviceability, $i=H, L$ \\
$s_{T i}$ & TTA's serviceability, $i=H, L$ \\
$\rho$ & The probability that the OTA believes that the TTA's serviceability is at a high state
\end{tabular}

Note that the superscript * denotes the optimal solutions.

$$
E \Pi_{T}=a+b\left(s_{O} e_{O}+s_{T} e_{T}+\theta\right)-\frac{\eta_{T} e_{T}^{2}}{2}-\frac{r \sigma^{2} b^{2}}{2} .
$$

Due to the uncertainty of the $\mathrm{O} 2 \mathrm{O}$ model market demand and equation (5), TTA's risk cost is $r \sigma^{2} b^{2} / 2$.

\section{Equilibrium Solutions and Analysis}

This paper mainly studies the service cooperation contract design of OTA creating $\mathrm{O} 2 \mathrm{O}$ model by cooperating with TTA under symmetric and asymmetric information. Further, the contract model with continuous type of TTA's serviceability under information asymmetry is researched. Here, the superscripts " $N$," " $S$," and " $C$ " represent the case of symmetric information, the discrete type, and continuous type of TTA's service capability under information asymmetry, respectively.
In the process of establishing service cooperation between an OTA and a TTA, the serviceability and effort are TTA's private information which OTA is difficult to observe. Similar to the study of Li et al. [30], it is assumed that there are two possibilities for TTA's serviceability: high serviceability $s_{T H}$ and low serviceability $s_{T L}$, and $s_{T H}>s_{T L}$.

4.1. Equilibrium of Symmetric Information. In the case of symmetric information, the OTA fully knows the state of TTA's serviceability $s_{T i}(i=H, L)$. The OTA designs a service contract $\left(a_{i}^{N}, b_{i}^{N}\right)$ and sale effort $e_{O i}^{N}$ when the type of TTA's serviceability is $i$. Then the expected revenue of OTA $E \Pi_{O}\left(a_{i}^{N}, b_{i}^{N}\right)$ and TTA $E \Pi_{T i}\left(a_{i}^{N}, b_{i}^{N}\right)$ and the optimization problem P1 is

$$
\left\{\begin{array}{l}
\max _{a_{i}^{N}, b_{i}^{N}, e_{O i}^{N}} E \Pi_{O}=\left(1-b_{i}^{N}\right)\left(\left(s_{O} e_{O i}^{N}+s_{T i} e_{T i}^{N}+\theta\right)-a_{i}^{N}-\frac{\eta_{O} e_{O i}^{N 2}}{2}\right), \\
\text { s.t. }(\mathrm{IR}-i) a_{i}^{N}+b_{i}^{N}\left(s_{O} e_{O i}^{N}+s_{T i} e_{T i}^{N}+\theta\right)-\frac{\eta_{T} e_{T i}^{N 2}}{2}-\frac{r \sigma^{2}\left(b_{i}^{N}\right)^{2}}{2} \geq \underline{\Pi_{T}},
\end{array}\right.
$$

where

$$
e_{T i}^{N}=\underset{e_{T}}{\arg \max }\left(a_{i}^{N}+b_{i}^{N}\left(s_{O} e_{O i}^{N}+s_{T i} e_{T i}^{N}+\theta\right)-\frac{\eta_{T} e_{T i}^{N 2}}{2}-\frac{r \sigma^{2}\left(b_{i}^{N}\right)^{2}}{2}\right)
$$

In the above optimization problem P1, the OTA maximizes its revenue. Inequality $(I R-i)$ is individual constraints, assuring that the TTA will join the service cooperation because of exceeding the reservation revenue $\Pi_{T}$. Equation
(7) denotes the TTA optimizes service effort by maximizing its revenue. The optimal decisions are found out by solving the above optimization problem P1 using the backward induction method. 
Theorem 1. In the case of symmetric information, given the type of TTA's serviceability as $i$, the OTA's optimal service contract $\left(a_{i}^{N *} b_{i}^{N *}\right)$, sale effort $e_{\mathrm{O} i}^{N *}$, and the TTA's optimal service effort $e_{T i}^{N *}$ are

$$
\begin{aligned}
b_{i}^{N *} & =\frac{s_{T i}^{2}}{s_{T i}^{2}+\eta_{T} r \sigma^{2}}, \\
a_{i}^{N *} & =\frac{\Pi_{T}}{}-\left(\frac{s_{O}^{2}}{\eta_{O}}+\theta\right) b_{i}^{N *}+\frac{1}{2}\left(r \sigma^{2}-\frac{s_{T i}^{2}}{\eta_{T}}\right)\left(b_{i}^{N *}\right)^{2}, \\
e_{O i}^{N *} & =\frac{s_{O}}{\eta_{O}}, \\
e_{T i}^{N *} & =\frac{s_{T i}^{3}}{\eta_{T}\left(s_{T i}^{2}+\eta_{T} r \sigma^{2}\right)}=\frac{s_{T i}}{\eta_{T}} b_{i}^{N *} .
\end{aligned}
$$

Theorem 1 shows that, (1) with the TTA's service cost coefficient $\eta_{T}$, market uncertainty $\sigma^{2}$, and risk aversion coefficient $r$ increasing, the service commission coefficient $b_{i}^{N *}$ decreases; (2) when the market scale $\theta$ and OTA's sale ability decreasing $s_{O}$ or OTA's sale cost coefficient $\eta_{O}$ increasing, the OTA's fixed payment increases $a_{i}^{N *}$, so as to encourage TTA to participate in cooperation for cocreating the $\mathrm{O} 2 \mathrm{O}$ model. In addition, $s_{O}$ and $\eta_{O}$ only affect OTA's fixed payment $a_{i}^{N *}$ but have no effect on service commission coefficient $b_{i}^{N *} ;(3)$ the OTA's online sales effort $e_{\mathrm{O} i}^{N *}$ is only related to its own saleability
$s_{O}$ and cost coefficient $\eta_{O}$ and is directly proportional to $s_{O}$ and inversely proportional to $\eta_{O}$; (4) with the service commission coefficient $b_{i}^{N *}$ and TTA's serviceability $s_{T i}$ increasing or TTA's service cost coefficient $\eta_{T}$ decreasing, the TTA's offline service effort $e_{T i}^{N *}$ increases.

4.2. Equilibrium of Asymmetric Information. In the case of asymmetric information, the TTA surely knows which of the two serviceability states will occur, while the OTA has only a subjective assessment about the likelihood of the two serviceability states. Let $\rho$ be the probability that the OTA believes that the TTA's serviceability is at a high state and $1-\rho$ be the probability of the low state. Due to its parsimony and tractability for analysis, this type of asymmetric information has been commonly employed in supply chain contracting $[15,27,30]$. In this paper, the OTA is an uninformed party that acts as a principal, and the TTA is an agent that holds private information about its serviceability. The service contract design problem is investigated under asymmetric serviceability information. The goal of the OTA is to design a menu of service contracts so as to maximize its expected profit based on the revelation principle.

When the state of TTA's serviceability is $i$ and OTA gives service contract $\left(a_{i}^{S}, b_{i}^{S}\right)$ and sale effort $e_{\mathrm{O} i}^{S}$, the revenue of OTA and TTA is $E \Pi_{O}\left(a_{i}^{S}, b_{i}^{S}\right)$ and $E \Pi_{T i}\left(a_{i}^{S}, b_{i}^{S}\right)$, respectively, and then the optimization problem $\mathrm{P} 2$ is

$$
\left\{\begin{array}{l}
\max _{a_{H}^{S}, b_{H}^{S}, e_{O H}^{S}, a_{L}^{S}, b_{L}^{S}, e_{O L}^{S}} E \Pi_{O}=\left\{\rho\left(\left(1-b_{H}^{S}\right)\left(s_{O} e_{O H}^{S}+s_{T H} e_{T H}^{S}+\theta\right)-a_{H}^{S}-\frac{\eta_{O} e_{O H}^{S 2}}{2}\right)+\right. \\
\left.(1-\rho)\left(\left(1-b_{L}^{S}\right)\left(s_{O} e_{O L}^{S}+s_{T H} e_{T L}^{S}+\theta\right)-a_{L}^{S}-\frac{\eta_{O} e_{O L}^{S 2}}{2}\right)\right\} \\
\text { s.t. }(\mathrm{IC}-H) a_{H}^{S}+b_{H}^{S}\left(s_{O} e_{O H}^{S}+s_{T H} e_{T H}^{S}+\theta\right)-\frac{\eta_{T} e_{T H}^{S 2}}{2}-\frac{r \sigma^{2} b_{H}^{2}}{2} \geq \\
a_{L}^{S}+b_{L}^{S}\left(s_{O} e_{O S}^{S}+s_{T H} e_{T H}^{L}+\theta\right)-\frac{\eta_{T} e_{T H}^{L 2}}{2}-\frac{r \sigma^{2} b_{L}^{2}}{2} \\
(\mathrm{IC}-L) a_{L}^{S}+b_{L}^{S}\left(s_{O} e_{O L}^{S}+s_{T L} e_{T L}^{S}+\theta\right)-\frac{\eta_{T} e_{T L}^{S 2}}{2}-\frac{r \sigma^{2} b_{L}^{2}}{2} \geq \\
(\mathrm{IR}-L) a_{L}^{S}+b_{L}^{S}\left(s_{O} e_{O L}^{S}+s_{T L} e_{T L}^{S}+\theta\right)-\frac{\eta_{T} e_{T L}^{S 2}}{2}-\frac{r \sigma^{2} b_{L}^{2}}{2} \geq \underline{\Pi_{T}} \\
(\mathrm{IR}-H) a_{H}^{S}+b_{H}^{S}\left(s_{O} e_{O H}^{S}+s_{T H} e_{T H}^{S}+\theta\right)-\frac{\eta_{T} e_{T H}^{S 2}}{2}-\frac{r \sigma^{2} b_{H}^{2}}{2} \geq \underline{\Pi_{T}}, \\
a_{H}^{S}+b_{H}^{S}\left(s_{O} e_{O H}^{S}+s_{T L} e_{T L}^{H}+\theta\right)-\frac{\eta_{T} e_{T L}^{H 2}}{2}-\frac{r \sigma^{2} b_{H}^{2}}{2},
\end{array}\right.
$$


where

$$
\begin{aligned}
& e_{T H}^{S}=\underset{e}{\arg \max }\left(a_{H}^{S}+b_{H}^{S}\left(s_{O} e_{\mathrm{OH}}^{S}+s_{T H} e_{T H}^{S}+\theta\right)-\frac{\eta_{T} e_{T H}^{S 2}}{2}-\frac{r \sigma^{2} b_{H}^{2}}{2}\right), \\
& e_{T L}^{S}=\underset{e}{\arg \max }\left(a_{L}^{S}+b_{L}^{S}\left(s_{O} e_{O L}^{S}+s_{T L} e_{T L}^{S}+\theta\right)-\frac{\eta_{T} e_{T L}^{S 2}}{2}-\frac{r \sigma^{2} b_{L}^{2}}{2}\right) .
\end{aligned}
$$

In the above optimization problem $\mathrm{P} 2$, the expected revenue of OTA $E \Pi_{O}$ is the sum of revenue under the cooperation of serviceability states of TTA. Inequalities (ICi) are incentive compatibility constraints, assuring that the TTA does not pretend to choose the other serviceability state, where $e_{T H}^{L}\left(e_{T L}^{H}\right)$ indicates the optimal service effort level of TTA under service reward contract $\left(a_{L}^{S}, b_{L}^{S}\right)$ $\left(\left(a_{H}^{S}, b_{H}^{S}\right)\right)$. Inequalities (IR-i) are individual rationality constraints, assuring that the TTA will join to cocreate $\mathrm{O} 2 \mathrm{O}$ model because of exceeding the reservation revenue $\Pi_{T}$. Equations (10) and (11) denote the TTA optimizes its service effort $e_{T i}^{N}$ by maximizing its revenue according to OTA's service cooperation contract $\left(a_{i}^{S} b_{i}^{S}\right)$ and sale effort $e_{O i}^{S}$. The optimal decisions are found out by solving the above optimization problem P2 using the backward induction method.

Theorem 2. Under asymmetric information, the OTA reveals TTA's serviceability by designing separation contracts. The OTA's service commission contract, optimal sale effort, and TTA's service effort are

$$
\begin{aligned}
& a_{H}^{S *}=\underline{\Pi_{T}}-\left(\frac{s_{O}^{2}}{\eta_{O}}+\theta\right) b_{H}^{S *}+\frac{1}{2}\left(r \sigma^{2}-\frac{s_{T H}^{2}}{\eta_{T}}\right)\left(b_{H}^{S *}\right)^{2}+\frac{1}{2 \eta_{T}}\left(s_{T H}^{2}-s_{T L}^{2}\right)\left(b_{L}^{S *}\right)^{2}, \\
& b_{H}^{S *}=\frac{s_{T H}^{2}}{s_{T H}^{2}+\eta_{T} r \sigma^{2}}, \\
& a_{L}^{S *}=\underline{\Pi_{T}}-\left(\frac{s_{O}^{2}}{\eta_{O}}+\theta\right) b_{L}^{S *}+\frac{1}{2}\left(r \sigma^{2}-\frac{s_{T L}^{2}}{\eta_{T}}\right)\left(b_{L}^{S *}\right)^{2}, \\
& b_{L}^{S *}=\frac{(1-\rho) s_{T L}^{2}}{s_{T L}^{2}-2 \rho s_{T L}^{2}+\rho s_{T H}^{2}+(1-\rho) \eta_{T} r \sigma^{2}}, \\
& e_{O H}^{S *}=e_{O L}^{S *}=\frac{s_{O}}{\eta_{O}}, \\
& e_{T H}^{S *}=\frac{s_{T H}^{3}}{\eta_{T}\left(s_{T H}^{2}+\eta_{T} r \sigma^{2}\right)}, \\
& e_{T L}^{S *}=\frac{(1-\rho) s_{T L}^{3}}{\left(s_{T L}^{2}-2 \rho s_{T L}^{2}+\rho s_{T H}^{2}+(1-\rho) \eta_{T} r \sigma^{2}\right) \eta_{T}} .
\end{aligned}
$$

Theorem 2 shows the following:

(1) When $r \longrightarrow+\infty, b_{H}^{S *}=b_{L}^{S *}=0$ and $a_{H}^{S *}=a_{L}^{S *}=$ $\Pi_{T}$ can be obtained. That is, when TTA has no risk tolerance, its revenue could only be equal to its reservation revenue. When $r \longrightarrow 0, \quad b_{H}^{S *}=1$ and $b_{L}^{S *}=\left(1 / 1+\rho\left(s_{T H}^{2}-s_{T L}^{2} /(1-\rho) s_{T L}^{2}\right)\right)<1$. That is, when the TTA tends to be risk-neutral, TTA with high serviceability will obtain the total revenue and if the difference between the two types of TTA's serviceability or the probability of TTA with high serviceability is greater, the OTA's service commission coefficient for TTA with low serviceability is lower. When $r>0$, with the increase of TTA's risk aversion coefficient, the service commission coefficient decreases correspondingly, indicating that risk aversion can offset the incentive effect of the service commission coefficient. 
(2) According to $\left(\partial b_{H}^{S *} / \partial s_{T H}\right) \geq 0\left(\partial b_{L}^{S *} / \partial s_{T L}\right) \geq 0$, the service commission coefficient will increase with the increasing TTA's serviceability.

(3) The service effort of the TTA with low serviceability has no effort on the service commission coefficient the TTA with high serviceability obtains. However, the difference between service effort of TTA with high and low service will affect the service commission coefficient TTA with low serviceability obtains, and the greater the difference is, the smaller the service commission coefficient is.

(4) According to $\left(\partial b_{H}^{S *} / \partial \rho\right)=0\left(\partial b_{L}^{S *} / \partial \rho\right) \leq 0$, the probability $\rho$ has no effect on service commission coefficient that the TTA with high serviceability obtains. However, with the increase of $\rho$, the service commission coefficient that the TTA with high serviceability obtains decreases.

(5) The relationship between service commission coefficient and TTA's service cost coefficient $\eta_{T}$, the degree of market uncertainty $\sigma^{2}$, the degree of risk aversion $r$, and the relationship between fixed payment and OTA's saleability and sale cost coefficient are the same under symmetric information, which is omitted here.
Corollary 1. For TTA with different serviceability, the optimal service commission contract parameters have the relationships $b_{H}^{S *} \geq b_{L}^{S *}$ and $a_{H}^{S *} \leq a_{L}^{S *}$.

Corollary 1 shows that the motivation purpose of OTA service contract is different for TTA with different serviceability. This means that the OTA should balance the motivation cooperation and the incentive of improving service effort for TTA when designing service commission contract. If the TTA is of a low serviceability type, the OTA will give TTA a larger fixed payment to ensure TTA's initiative in cocreating the $\mathrm{O} 2 \mathrm{O}$ model. If the TTA is of a high serviceability state, the OTA will give a larger service commission coefficient. And according to $b_{H}^{S *}-b_{L}^{S *}=\left(\left(s_{T H}^{2}-s_{T L}^{2}\right) \quad\left(\rho s_{T H}^{2}+(1-\rho) \quad \eta_{T} r \sigma^{2}\right) /\right.$ $\left.\left(s_{T H}^{2}+\eta_{T} r \sigma^{2}\right)\left(s_{T L}^{2}-2 \rho s_{T L}^{2}+\rho s_{T H}^{2}+(1-\rho) \eta_{T} r \sigma^{2}\right)\right) \geq 0$, the greater the difference between service efforts of TTA with high and low service, the bigger the difference of service commission coefficient.

\subsection{Comparison of Results under Symmetric and Asymmetric Information}

4.3.1. Validity of Separation Service Contract. By introducing the results of Theorem 2 into incentive compatibility constraints (IC-i) and comparing the TTA's revenue of TTA false and truthfulness reporting serviceability, it is obtained as

$$
\begin{aligned}
& E \Pi_{T H}\left(a_{H}^{S *}, b_{H}^{S *}\right)-E \Pi_{T H}\left(a_{L}^{S *}, b_{L}^{S *}\right)=0, \\
& E \Pi_{T L}\left(a_{L}^{S *}, b_{L}^{S *}\right)-E \Pi_{T L}\left(a_{H}^{S *}, b_{H}^{S *}\right)=\frac{\left(b_{H}^{S *}-b_{L}^{S *}\right)\left(b_{H}^{S *}+b_{L}^{S *}\right)\left(s_{T H}+s_{T L}\right)}{2 \eta_{T}}>0 .
\end{aligned}
$$

When the TTA with low serviceability pretends to be the TTA with high serviceability, the revenue is strictly lower than that when TTA truthfully reports serviceability $\left(E \Pi_{T L}\left(a_{H}^{S *}, b_{H}^{S *}\right)<E \Pi_{T L}\left(a_{L}^{S *}, b_{L}^{S *}\right)\right)$. Therefore, the TTA with low serviceability has no motivation to disguise the TTA with high serviceability. In addition, if the TTA is of a high serviceability type, its false report will not affect its revenue $\left(E \Pi_{T H}\left(a_{H}^{S *}, b_{H}^{S *}\right)=E \Pi_{T H}\left(a_{L}^{S *}, b_{L}^{S *}\right)\right)$. Therefore, the TTA with high serviceability has no motivation to disguise TTA with low serviceability. It can be seen that separation of service contract has the characteristics of "self-selection" in the OTA and TTA cocreating $\mathrm{O} 2 \mathrm{O}$ model. That is, the TTA with high or low serviceability needs to choose the service contract corresponding to its serviceability type.

Corollary 2. By comparing the expected revenue and the reservation revenue with different serviceability types, it is obtained as

$$
\begin{aligned}
& E \Pi_{T}\left(s_{T L}\right)=\underline{\Pi_{T}}, \\
& E \Pi_{T}\left(s_{T H}\right)=\underline{\Pi_{T}}+\frac{\left(s_{T H}^{2}-s_{T L}^{2}\right)}{2 \eta_{T}} b_{L}^{S * 2} .
\end{aligned}
$$

Corollary 2 shows that when the TTA is of a low serviceability type, TTA's revenue is reservation revenue after accepting the service commission contract. However, when the revenue of TTA with high serviceability is greater than reservation revenue, the difference $\left(\left(s_{T H}^{2}-s_{T L}^{2}\right) / 2 \eta_{T}\right) b_{L}^{S * 2}$ shows that, in order to obtain private information of TTA's serviceability, the OTA needs to pay TTA information sharing fees. If the OTA does not pay the information fee, TTA may lie about its serviceability and damage the OTA's expected revenue.

4.3.2. The Impact of Information Asymmetric on Service Contract and Expected Revenue. According to Theorems 1 and 2, by comparing and analyzing the service contract, TTA's optimal service effort, and the revenues of the partners under symmetric and asymmetric information conditions, Theorems 3 and 4 are obtained.

Theorem 3. The optimal service contract, sale effort, and TTA optimal service effort under symmetry and asymmetry information have the following relationships: 

(1) $a_{H}^{S *} \geq a_{H}^{N *}, b_{H}^{N *}=b_{H}^{S *}$
(2) $a_{L}^{S *} \geq a_{L}^{N *}, b_{L}^{S *} \leq b_{L}^{N *}$
(3) $e_{T H}^{N *}=e_{T H}^{S *}, e_{T L}^{S *}<e_{T L}^{N *}$
(4) $e_{\mathrm{O} i}^{N *}=e_{\mathrm{O} i}^{S *}$

In Theorem 3, (1) and (2) show that the OTA should pay a higher fixed payment to mobilize TTA to participate in cocreating the $\mathrm{O} 2 \mathrm{O}$ model under asymmetric information. If the TTA is of a low serviceability type, the OTA lacks motivation to encourage TTA to provide higher service effort, and the service commission coefficient is "distorted downward." If the TTA is of a high serviceability type, the OTA will provide a higher service commission coefficient to encourage the TTA to provide higher service effort under asymmetrical information. Here, the TTA can obtain additional information rent by "upward distorted" fixed payment. This also means that, due to the existence of asymmetric information, the service contract design of OTA needs to adjust the fixed payment and service commission coefficient to ensure that TTA can participate in cooperation and choose the appropriate level of service efforts that are beneficial to OTA. From (3), the service effort of TTA with the high serviceability is the same in symmetrical and asymmetrical information, and the service effort of TTA with the low serviceability is lower in asymmetrical information than that in symmetrical information. Therefore, the OTA is dominant in encouraging low serviceability type TTA to participate in cooperation, which will also provide incentives to participate in cooperation and service efforts to TTA with high serviceability state. (4) shows that the OTA's optimal sale effort is the same in symmetrical and asymmetrical information. This is straightforward because the OTA knows its own saleability information.
Theorem 4. There is the following relationship between OTA's and TTA's expected revenue under symmetry and asymmetry information:

(1) $E \Pi_{O i}^{S *} \leq E \Pi_{O i}^{N *}$

(2) $E \Pi_{T H}^{S *} \geq E \Pi_{T H}^{N *}$

(3) $E \Pi_{T L}^{S *}=E \Pi_{T L}^{N *}$

Theorem 4 shows that the information disadvantage of OTA is detrimental to its expected revenue; the information advantage of TTA does not necessarily generate information rent. When the TTA is the high serviceability type, the increase of fixed payment cost and constant service commission coefficient make OTA pay higher service commission. Therefore, the TTA with high serviceability can get additional information rent from the increased fixed payment. When the TTA is of a low serviceability type, the asymmetric information makes the service commission coefficient tilt downward and fixed payment cost rise, and the rise of fixed payment can make up for the loss of TTA caused by the decline of service commission coefficient. Therefore, the expected revenue of TTA with low serviceability remains unchanged.

4.4. Strategic Analysis When TTA's Service Ability Is Continuous. Assuming that TTAs' service capability is continuously distributed and satisfied $s_{T} \in H=\left[s_{T}, \overline{s_{T}}\right]$, $F\left(s_{T}\right)$ and $f\left(s_{T}\right)$ are TTA's cumulative distribution and distribution density function, respectively, and $f\left(s_{T}\right)>0$.

Due to the fact that $\xi$ is not related to $s_{T}$, the expected revenue of risk-neutral OTA can be obtained as

$$
E \Pi_{O}\left(s_{T}\right)=\int_{\underline{s_{T}}}^{\overline{s_{T}}}\left\{\left(1-b^{C}\left(s_{T}\right)\right)\left(s_{O} e_{O}^{C}\left(s_{T}\right)+s_{T}^{C} e_{T}^{C}\left(s_{T}\right)+\theta\right)-a^{C}\left(s_{T}\right)-\frac{\eta_{O} e_{O}^{C 2}\left(s_{T}\right)}{2}\right\} f\left(s_{T}\right) \mathrm{d} s_{T} .
$$

The expected revenue of TTA is

$$
\begin{aligned}
E \Pi_{T}\left(s_{T}\right)= & a^{C}\left(s_{T}\right)+b^{C}\left(s_{T}\right)\left(s_{O} e_{O}^{C}\left(s_{T}\right)+s_{T}^{C} e_{T}^{C}\left(s_{T}\right)+\theta\right) \\
& -\frac{\eta_{T} e_{T}^{C 2}\left(s_{T}\right)}{2}-\frac{r \sigma^{2} b^{C 2}\left(s_{T}\right)}{2} .
\end{aligned}
$$

Firstly, determine the service effort level of TTA $e_{T}^{C}\left(s_{T}\right)$; that is, $\forall s_{T} \in H, e_{T}^{C}\left(s_{T}\right)=\operatorname{argmax}_{e} E \Pi_{T}\left(s_{T}\right)==\left(s_{T}^{C} b^{C}\left(s_{T}\right) / \eta_{T}\right)$.
Bringing $e_{T}^{C}\left(s_{T}\right)$ to equation (16), it is obtained as

$$
\begin{aligned}
E \Pi_{T}\left(s_{T}\right)= & a^{C}\left(s_{T}\right)+\left(s_{O} e_{O}^{C}\left(s_{T}\right)+\theta\right) b^{C}\left(s_{T}\right) \\
& +\frac{1}{2}\left(\frac{s_{T}^{2}}{\eta_{T}}-r \sigma^{2}\right) b^{C 2}\left(s_{T}\right) .
\end{aligned}
$$

Furthermore, when $s_{T}$ is continuous, the optimization problem P3 is

$$
\begin{aligned}
& \max _{a^{C}, b^{C}} \int_{\underline{s_{T}}}^{\overline{s_{T}}}\left\{\left(1-b^{C}\left(s_{T}\right)\right)\left(s_{O} e_{O}^{C}\left(s_{T}\right)+s_{T}^{C} e_{T}^{C}\left(s_{T}\right)+\theta\right)-a^{C}\left(s_{T}\right)-\frac{\eta_{O} e_{O}^{C 2}\left(s_{T}\right)}{2}\right\} f\left(s_{T}\right) \mathrm{d} s_{T} \\
& \text { s.t. (IC) } b^{C}\left(s_{T}\right) \geq 0, \\
& \text { (IC) } a^{C}\left(s_{T}\right)+s_{O} e_{O}^{C}\left(s_{T}\right) b^{C}\left(s_{T}\right)+\left(s_{O} e_{O}^{C}\left(s_{T}\right)+\theta\right) b^{C}\left(s_{T}\right)+\left(\frac{s_{T}^{C 2}}{\eta_{T}}-r \sigma^{2}\right) b^{C}\left(s_{T}\right)=0,
\end{aligned}
$$




$$
(\mathrm{IR}) a^{C}\left(s_{T}\right)+\left(s_{O} e_{O}^{C}\left(s_{T}\right)+\theta\right) b^{C}\left(s_{T}\right)+\frac{1}{2}\left(\frac{s_{T}^{2}}{\eta_{T}}-r \sigma^{2}\right) b^{C 2}\left(s_{T}\right) \geq \underline{\Pi_{T}},
$$

where $e_{T}^{C}\left(s_{T}\right)=\left(s_{T}^{C} b^{C}\left(s_{T}\right) / \eta_{T}\right)$.

Theorem 5. When $\left(d / d s_{T}\right)\left(1-F\left(s_{T}\right) / s_{T} f\left(s_{T}\right)\right)<0$,

$$
\begin{aligned}
a^{C *}\left(s_{T}\right) & =\underline{\Pi_{T}}-\left(\frac{s_{O}^{2}}{\eta_{O}}+\theta\right) b^{C *}\left(s_{T}\right)-\frac{1}{2}\left(\frac{s_{T}^{2}}{\eta_{T}}-r \sigma^{2}\right) b^{C * 2}\left(s_{T}\right)+\int_{\underline{s_{T}}}^{s_{T}} \frac{\omega}{\eta_{T}} b^{C 2}(\omega) \mathrm{d} \omega, \\
b^{C *}\left(s_{T}^{C}\right) & =\frac{1}{1+\left(\eta_{T} r \sigma^{2} / s_{T}^{C 2}\right)+\left(2\left(1-F\left(s_{T}^{C}\right)\right) / s_{T}^{C} f\left(s_{T}^{C}\right)\right)}, \\
e_{O}^{C *} & =\frac{s_{O}}{\eta_{O}} \\
e_{T}^{C *}\left(s_{T}\right) & =\frac{s_{T}^{C} b^{C *}\left(s_{T}\right)}{\eta_{T}} .
\end{aligned}
$$

Theorem 5 shows that when the serviceability of TTA is continuous, $\left(\mathrm{d} / \mathrm{d} s_{T}\right)\left(1-F\left(s_{T}\right) / s_{T} f\left(s_{T}\right)\right)<0$ is the precondition for the existence of a service commission separation contract. At this time, $b^{C *}\left(s_{T}\right)$ is strictly increasing, and all TTA can choose appropriate service contracts corresponding to its serviceability type.

Corollary 3. $E \Pi_{T}\left(s_{T}\right)-\underline{\Pi_{T}}=\int_{\underline{s_{T}}}^{s_{T}}\left(\omega / \eta_{T}\right) b^{C * 2}(\omega) d \omega$.

Corollary 3 shows that, apart from the TTA with the worst serviceability, all other types of TTA can get strict information rent. With the increase of TTA's serviceability, the information rent and the excepted revenue of TTA increase, which is consistent with the conclusion when TTA's serviceability is discrete.

\section{Numerical and Sensitivity Analysis}

The impacts of the risk aversion coefficient, serviceability, and asymmetric information on OTA service contract and both TTA and OTA's revenue are analyzed so as to get more management implications. Considering that the references on cooperation between the TTA and OTA are less and numerical examples are usually hypothetical, the values of parameters are assigned according to Jin et al. [15]. A selected set of parameters is as follows: $s_{O}=0.3$, $\eta_{O}=0.1, \eta_{T}=0.3, s_{T H}=0.5, s_{T L}=0.5, \rho=0.5, \theta=0, \sigma^{2}=4$, and $\Pi_{T}=5$. In order to study the impacts of TTA's risk aversion coefficient $r$ and serviceability $s_{T i}$ on the service commission and revenue of both TTA and OTA, take $s_{T i}$ as the horizontal axis; that is, when $s_{T H}=0.5$ and $s_{T L} \in(0.2,0.5)$ or when $s_{T L}=0.5$ and $s_{T H} \in(0.5,1)$, fixed payment, service commission coefficient, and revenue under symmetric information and asymmetric information are plotted, respectively, with $r=0.1, r=0.5$, and $r=0.9$. The results of numerical examples are summarized in Figures 1-3.
5.1. Analysis of the Parameters of Service Commission Contract. Figure 1 shows that (1) when TTA's serviceability $s_{T i}$ increases, fixed payment of $a_{i}^{S *}$ and $a_{i}^{N *}$ always decreases, but $a_{i}^{S *}>a_{i}^{N *}$. This is straightforward because OTA needs to give TTA more fixed payment to stimulate its initiative to cooperate and create an $\mathrm{O} 2 \mathrm{O}$ model under asymmetric information; (2) when $r$ takes different values, the influence of asymmetric information on fixed payment increases with the increase of the difference between TTA's serviceability, which indicates that the smaller the difference between TTA's different serviceability, the smaller the influence of asymmetric information on fixed payment; (3) no matter the serviceability type of TTA is, $a_{i}^{S *}$ and $a_{i}^{N *}$ increase and the distance between fixed payment curves decreases with the increase in $r$, indicating that $r$ can alleviate the impact of asymmetric information on fixed payment.

Figure 2 shows that (1) when TTA's serviceability $s_{T i}$ increases, service commission coefficient of $b_{i}^{S *}$ and $b_{i}^{N *}$ always increases, and $b_{H}^{S *}=b_{H}^{N *}$ and $b_{L}^{S *}<b_{L}^{N *}$. This indicates that the existence of asymmetric information does not affect the service commission coefficient of OTA paid for TTA with high serviceability, but it will reduce the service commission coefficient of OTA paid for TTA with low serviceability; (2) no matter the serviceability type of TTA is, $b_{i}^{S *}$ and $b_{i}^{N *}$ decrease with the increase in $r$, indicating that $r$ can offset the incentive effect of service commission coefficient on TTA; (3) Figure 2(b) shows the distance between service commission coefficient curves decreases with $r$ or $s_{T L}$ increases, which indicates that $r$ can alleviate the impact of asymmetric information on service commission coefficient and the smaller the difference between TTA's different serviceability, the smaller the influence of asymmetric information on service commission coefficient.

5.2. Revenue Analysis of Both TTA and OTA. Figure 3 shows that (1) no matter the serviceability type of TTA is, there is $\Delta E \Pi_{\mathrm{O} i}^{S N}<0$, indicating that the existence of asymmetric 


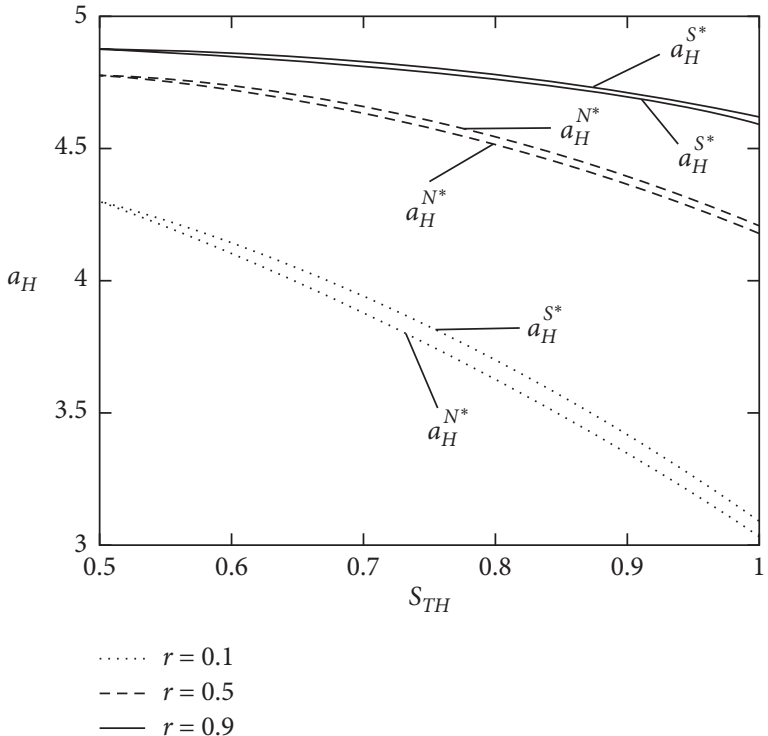

(a)

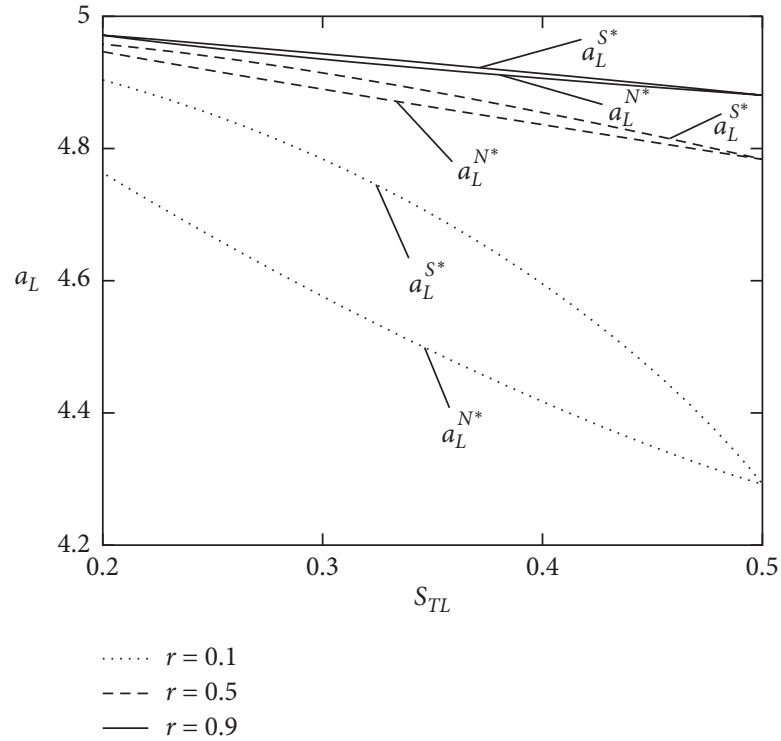

(b)

FIGURE 1: Impacts of $\mathrm{r}$ and $s_{T i}$ on fixed payment. (a) $s_{T L}=0.5$. (b) $s_{T H}=0.5$.

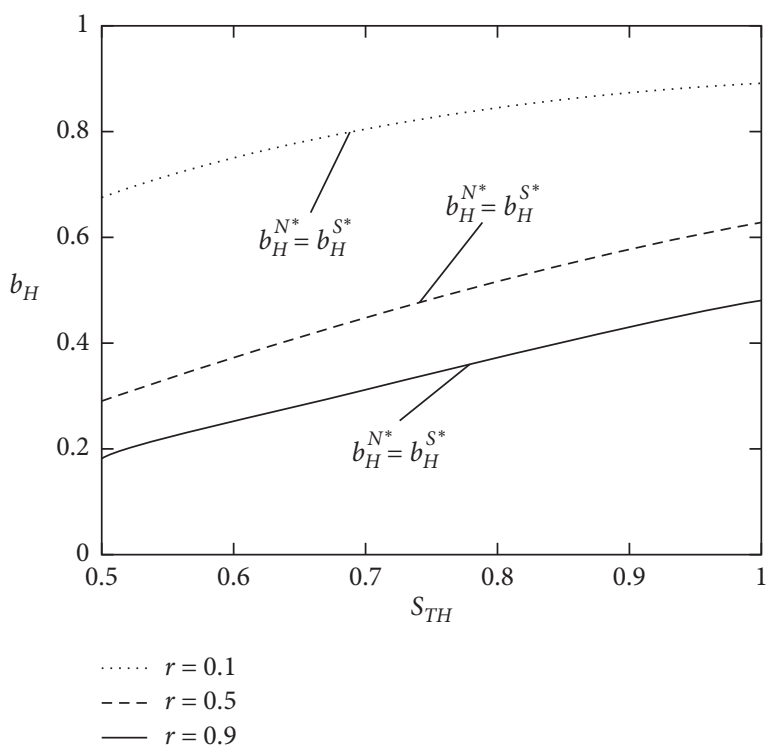

(a)

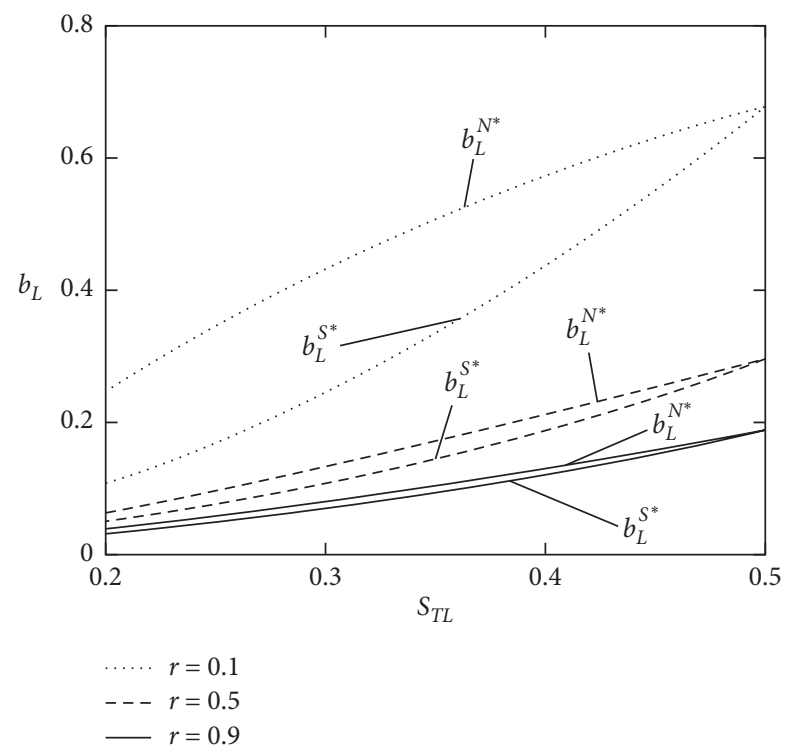

(b)

Figure 2: Impacts of $\mathrm{r}$ and $s_{T i}$ on service compensation coefficient. (a) $s_{T L}=0.5$. (b) $s_{T H}=0.5$.

information always leads to loss of OTA expected revenue. $\Delta E \Pi_{T H}^{S N *}>0$ and $\Delta E \Pi_{T L}^{S N *}=0$ show that only TTA with high serviceability can obtain additional information rent. $\triangle E \Pi_{T H}^{S N *}$ and $\triangle E \Pi_{O H}^{S N *}$ are symmetric with respect to the 0 value curve, which shows that, in the $\mathrm{O} 2 \mathrm{O}$ model composed by TTA and OTA, the existence of asymmetric information transfers part of revenue from OTA to TTA with high service capability; (2) when $s_{T H}$ increases, $\triangle E \Pi_{O i}^{S N *}$ firstly decreases and then increases. The changing trend of $\triangle E \Pi_{O H}^{S N *}$ depends on whether OTA's revenue from the improvement of TTA's serviceability can compensate for the cost of information value; (3) $\left|\Delta E \Pi_{\mathrm{Oi}}^{S N}\right|$ decreases with $r$ increases, which shows that $r$ can alleviate the 


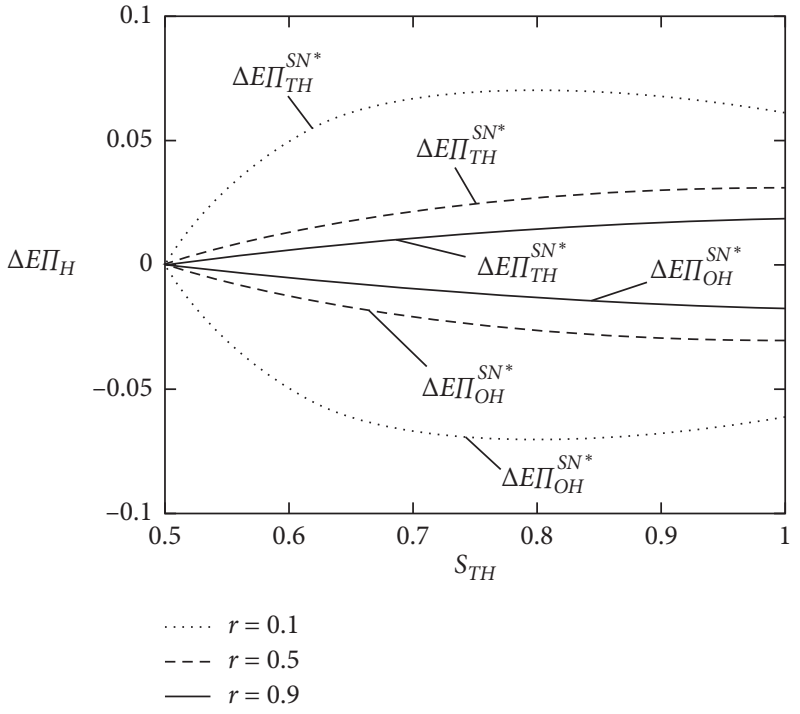

(a)

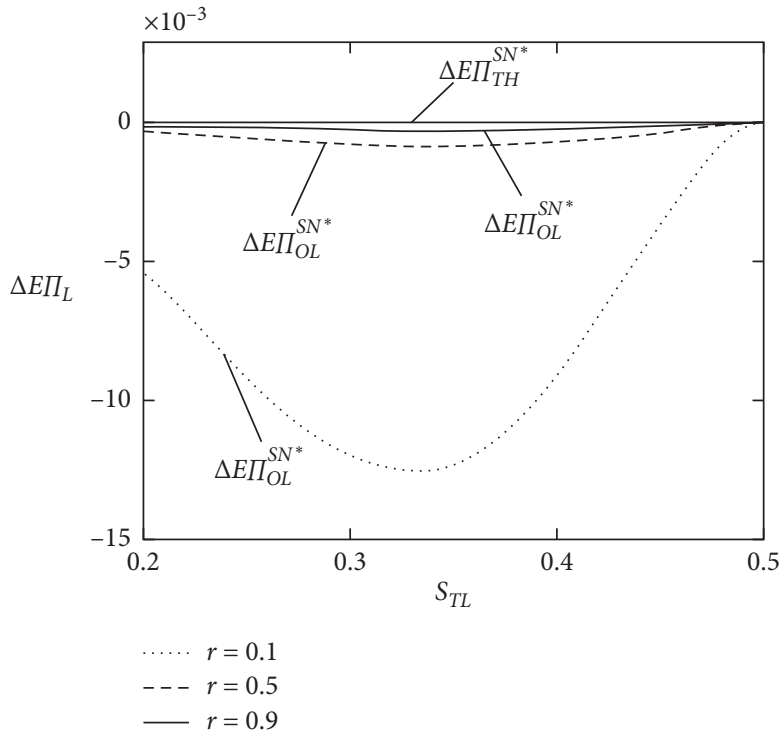

(b)

Figure 3: Impacts of $\mathrm{r}$ and $s_{T i}$ on $\Delta E \Pi_{T i}^{S N *}$ and $\Delta E \Pi_{O i}^{S N *}$. (a) $s_{T L}=0.5$. (b) $s_{T H}=0.5$.

adverse effect of OTA's information disadvantage. $\Delta E \Pi_{T H}^{S N *}$ decreases with $r$ increases, which indicates that $r$ can inhibit the information advantage of TTA with high serviceability.

\section{Conclusion and Future Research}

The rationality of the OTA service commission contract is an important factor to ensure the efficient operation of the $\mathrm{O} 2 \mathrm{O}$ model in the establishment of service cooperation between OTA and TTA. Considering the serviceability information asymmetry, the OTA designs reasonable service commission contracts to differentiate TTA serviceability and motivate TTA to improve service effort level. Some suggestions for establishing a cooperation contract are provided:

(1) When an OTA has low saleability or high sale cost, the OTA will increase the fixed payment to the TTA to support the cocreation of the $\mathrm{O} 2 \mathrm{O}$ model. The incentive effect of the service commission coefficient can be offset by the TTA's service effort cost coefficient, risk aversion coefficient, and the degree of market uncertainty.

(2) When the type of TTA's serviceability is continuous, the precondition of separation contract is $\left(\mathrm{d} / \mathrm{d} s_{T}\right)\left(1-F\left(s_{T}\right) / s_{T} f\left(s_{T}\right)\right)<0$. At this time, the TTA can choose the appropriate contract corresponding to its serviceability type.

(3) In cocreating the $\mathrm{O} 2 \mathrm{O}$ model, the existence of asymmetric information always results in the loss of OTA's expected revenue. Except for TTA with the lowest serviceability, all other types of TTA can obtain strict information rent. The stronger the TTA serviceability is, the more information rent it obtains and the greater its expected revenue is.

(4) The OTA designs service contracts by weighing the different incentives of fixed payments and service commission coefficient to the TTA. When the TTA is a high serviceability type, the OTA sets a high service commission coefficient to encourage the TTA to make more service. When the TTA is of a low serviceability type, the OTA sets a larger fixed payment, stimulating its enthusiasm for participating in cocreating the $\mathrm{O} 2 \mathrm{O}$ model.

Due to some of its basic assumptions, there are still some limitations of this paper. Firstly, in this paper, the service commission contract is considered as a linear form. In future research, it can be extended by other service cooperation forms, for example, service costsharing contract. Secondly, this study only considers that an OTA establishes service cooperation with a TTA or multiple TTAs. The next step is to extend this model, in which two or more OTAs achieve the $\mathrm{O} 2 \mathrm{O}$ model by service cooperation with multiple TTAs. Thirdly, the optimal service commission contract is studied from a short-term perspective. However, in some cases, longterm cooperation is more conducive to the stable development of both. For example, He et al. studied sustainable tourism by using evolutionary game models [31, 32]. Although it is more complex and challenging, service cooperation could be discussed from a long-term perspective. Finally, our paper mainly utilizes an analytical approach. Thus, another future research direction is to conduct empirical research to validate our analytical findings.

\section{Appendix}

\section{Proof of TTA's revenue}

Assuming that the random variable $x$ follows normal distribution $x \sim N\left(m, n^{2}\right)$, its utility function are the same as TTA's: $U(x)=-e^{-r x}$, and its expected utility is 


$$
\mathrm{EU}(x)=\int_{-\infty}^{+\infty}-e^{-r x} \frac{1}{\sqrt{2 \pi n}} e^{-\left((x-m)^{2} / 2 n^{2}\right)} \mathrm{d} x=-e^{-r\left(m-r n^{2} / 2\right)}
$$

According to certainty equivalence method $E U=U(C E)$, $-e^{-r(\mathrm{CE})}=-e^{-r\left(m-r n^{2} / 2\right)}$ can be obtained and also $\mathrm{CE}=m-$ $\left(r n^{2} / 2\right)$ can be get. According to $\xi \in N\left(0, \sigma^{2}\right), E \Pi_{T}=a+b$ $\left(s_{O} e_{O}+s_{T} e_{T}+\theta\right)-\left(\eta_{T} e_{T}^{2} / 2\right), \operatorname{Var}\left(\Pi_{T}\right)=b^{2} \sigma^{2}$. The TTA's revenue $\Pi_{T}$ is regarded as a random variable $x$, its certainty equivalent revenue is $a+b\left(s_{O} e_{O}+s_{T} e_{T}+\theta\right)-$ $\left(\eta_{T} e_{T}^{2} / 2\right)-\left(r \sigma^{2} b^{2} / 2\right)$

Proof of Theorem A.1. The optimization problem P1 is solved by using reverse induction and K-T method. The process is solved in two steps.
(1) The TTA's response function is $e_{T i}^{N}=\left(s_{T i} b_{i}^{N} / \eta_{T}\right)$, with a given service contract $\left(a_{i}^{N} b_{i}^{N}\right)$, and sale effort $e_{\mathrm{O} i}^{N}$.

(2) Solving OTA's optimal service contract and sale effort.

Plugging $e_{T i}^{N}$ back to optimization problem $\mathrm{P} 1$, it is easy to know that the OTA's expected revenue $E \Pi_{O}$ is linear function of $a_{i}^{N}$ and a joint concave of $b_{i}^{N}$ and $e_{O i}^{N}$. Therefore, there are corner solution $a_{i}^{N}$ and interior solution $b_{i}^{N}$ and $e_{\mathrm{O} i}^{N}$ under the constraint equation (IR). That is, there exists a unique optimal solution. The Lagrange function is constructed as

$$
\begin{aligned}
L\left(a_{i}^{N}, b_{i}^{N}, e_{\mathrm{O} i}^{N}\right)= & \left(1-b_{i}^{N}\right)\left(\left(s_{O} e_{\mathrm{O} i}^{N}+s_{T i} e_{T i}^{N}+\theta\right)-a_{i}^{N}-\frac{\eta_{O} e_{O i}^{N 2}}{2}\right) \\
& +\chi\left(a_{i}^{N}+b_{i}^{N}\left(s_{O} e_{O i}^{N}+s_{T i} e_{T i}^{N}+\theta\right)-\frac{\eta_{T} e_{T i}^{N 2}}{2}-\frac{r \sigma^{2}\left(b_{i}^{N}\right)^{2}}{2}-\underline{\Pi_{T}}\right) .
\end{aligned}
$$

Let $\left(\partial L / \partial a_{i}^{N}\right)=\left(\partial L / \partial b_{i}^{N}\right)=\left(\partial L / \partial e_{O i}^{N}\right)=0, \quad(\partial L / \partial \chi) \geq$ $0, \chi \geq 0$ and. $\chi(\partial L / \partial \chi)=0$

The only set of solutions can be obtained $\left(a_{i}^{N *} b_{i}^{N *} e_{\mathrm{Oi}}^{N *}\right)$.

Proof of Theorem A.2. The optimization problem P2 is solved by using reverse induction and K-T method. The process is solved in two steps.

(1) The TTA's response function can be obtained $e_{T i}^{S}=\left(s_{T i} b_{i}^{S} / \eta_{T}\right)$, with a given service contract $\left(a_{i}^{S} b_{i}^{S}\right)$, and sale effort $e_{\mathrm{O} i}^{S}$.
(2) Solving OTA's optimal service contract and sale effort.

Plugging $e_{T i}^{S}$ back to optimization problem $\mathrm{P} 2$, it is easy to know that the OTA's expected revenue $E \Pi_{O}$ is linear function of $a_{i}^{S}$ and a joint concave of $b_{i}^{S}$ and $e_{\mathrm{O} i}^{S}$. Therefore, there are corner solution $a_{i}^{S}$ and interior solution $b_{i}^{S}$ and $e_{\mathrm{O} i}^{S}$ under the constraint equation (IR-i). It is easy to prove that (IC-H) and (IR-L) are tight constraints, so the above optimization problem P2 can be rewritten as follows P2'

$$
\left\{\begin{array}{l}
\max _{a_{H}^{S}, b_{H}^{S}, e_{O H}^{S}, a_{L}^{S}, b_{L}^{S}, e_{O L}^{S}} E \Pi_{O}=\left\{\rho\left(\left(1-b_{H}^{S}\right)\left(s_{O} e_{O H}^{S}+\frac{b_{H}^{S} s_{T H}^{2}}{\eta_{T}}+\theta\right)-a_{H}^{S}-\frac{\eta_{O} e_{O H}^{S 2}}{2}\right)+(1-\rho) \times\right. \\
\left.\left(\left(1-b_{L}^{S}\right)\left(s_{O} e_{O L}^{S}+\frac{b_{L}^{S} s_{T L}^{2}}{\eta_{T}}+\theta\right)-a_{L}^{S}-\frac{\eta_{O} e_{O L}^{S 2}}{2}\right)\right\} \\
\text { s.t. }(\mathrm{IC}-H) a_{H}^{S}+b_{H}^{S}\left(\left(s_{O} e_{O H}^{S}+\theta\right)+\frac{\left(b_{H}^{S} s_{T H}\right)^{2}}{2 \eta_{T}}-\frac{r \sigma^{2} b_{H}^{2}}{2} \geq\right. \\
a_{L}^{S}+b_{L}^{S}\left(s_{O} e_{O L}^{S}+\theta\right)+\frac{\left(b_{L}^{S} s_{T H}\right)^{2}}{2 \eta_{T}}-\frac{r \sigma^{2} b_{L}^{2}}{2} \\
(\mathrm{IR}-L) a_{L}^{S}+b_{L}^{S}\left(s_{O} e_{O L}^{S}+\theta\right)+\frac{\left(b_{L}^{S} s_{T L}\right)^{2}}{2 \eta_{T}}-\frac{r \sigma^{2} b_{L}^{2}}{2} \geq \underline{\Pi_{T}} .
\end{array}\right.
$$


The Lagrange function is constructed as

$$
\begin{aligned}
L\left(a_{H}, b_{H}, e_{O H}, a_{L}, b_{L}, e_{O L}, \chi_{1}, \chi_{2}\right)= & \rho\left(\left(1-b_{H}^{S}\right)\left(s_{O} e_{O H}^{S}+\frac{b_{H}^{S} s_{T H}^{2}}{\eta_{T}}+\theta\right)-a_{H}^{S}-\frac{\eta_{O} e_{O H}^{S 2}}{2}\right)+(1-\rho) \times \\
& \cdot\left(\left(1-b_{L}^{S}\right)\left(s_{O} e_{O L}^{S}+\frac{b_{L}^{S} s_{T L}^{2}}{\eta_{T}}+\theta\right)-a_{L}^{S}-\frac{\eta_{O} e_{O L}^{S 2}}{2}\right)+\chi_{1}\left(a_{L}^{S}+b_{L}^{S}\left(s_{O} e_{O L}^{S}+\theta\right)+\frac{\left(b_{L}^{S} s_{T L}\right)^{2}}{2 \eta_{T}}-\frac{r \sigma^{2} b_{L}^{S 2}}{2}-\frac{\Pi_{R}}{2}\right) \\
& +\chi_{2}\left(a_{H}^{S}+b_{H}^{S}\left(s_{O} e_{O H}^{S}+\theta\right)+\frac{\left(b_{H}^{S} s_{T H}\right)^{2}}{2 \eta_{T}}-\frac{r \sigma^{2} b_{H}^{S 2}}{2}-a_{L}^{S}-b_{L}^{S}\left(s_{O} e_{O L}^{S}+\theta\right)-\frac{\left(b_{L}^{S} s_{T H}\right)^{2}}{2 \eta_{T}}+\frac{r \sigma^{2} b_{L}^{S 2}}{2}\right) .
\end{aligned}
$$

The Kuhn-Tucker condition is obtained as

$$
\frac{\partial L}{\partial a_{i}^{S}}=\frac{\partial L}{\partial b_{i}^{S}}=\frac{\partial L}{\partial e_{O i}^{S}}=0, \quad \frac{\partial L}{\partial \chi_{1}} \geq 0, \frac{\partial L}{\partial \chi_{2}} \geq 0,
$$

where $\chi_{1} \geq 0$ and $\chi_{1}\left(\partial L / \partial \chi_{1}\right)=0, \chi_{2} \geq 0$ and $\chi_{2}\left(\partial L / \partial \chi_{2}\right)=0$.

$$
\begin{aligned}
& b_{H}^{S *}-b_{L}^{S *}=\frac{\left(s_{T H}^{2}-s_{T L}^{2}\right)\left(\rho s_{T H}^{2}+(1-\rho) \eta_{T} r \sigma^{2}\right)}{\left(s_{T H}^{2}+\eta_{T} r \sigma^{2}\right)\left(s_{T L}^{2}-2 \rho s_{T L}^{2}+\rho s_{T H}^{2}+(1-\rho) \eta_{T} r \sigma^{2}\right)} \geq 0, \\
& a_{H}^{S *}-a_{L}^{S *}=\left(\left(\frac{s_{O}^{2}}{\eta_{O}}+\theta\right)-\frac{1}{2}\left(r \sigma^{2}-\frac{s_{T H}^{2}}{\eta_{T}}\right)\left(b_{L}^{S *}+b_{H}^{S *}\right)\right)\left(b_{L}^{S *}-b_{H}^{S *}\right) .
\end{aligned}
$$

When $r>0$, let

$$
G(r)=\left(\frac{s_{O}^{2}}{\eta_{O}}+\theta\right)-\frac{1}{2}\left(r \sigma^{2}-\frac{s_{T H}^{2}}{\eta_{T}}\right)\left(b_{L}^{S *}+b_{H}^{S *}\right)=\left(\frac{s_{O}^{2}}{\eta_{O}}+\theta\right)+\frac{s_{T H}^{2}}{2 \eta_{T}}\left(b_{L}^{S *}+b_{H}^{S *}\right)-\frac{1}{2} r \sigma^{2}\left(b_{L}^{S *}+b_{H}^{S *}\right),
$$

where $\left(s_{T H}^{2} / 2 \eta_{T}\right)\left(b_{L}^{S *}+b_{H}^{S *}\right)$ is about $r$ monotonically decreasing.

$$
\begin{aligned}
\frac{1}{2} r \sigma^{2}\left(b_{L}^{S *}+b_{H}^{S *}\right) & =\frac{1}{2} r \sigma^{2}\left(\frac{s_{T H}^{2}}{s_{T H}^{2}+\eta_{T} r \sigma^{2}}+\frac{(1-\rho) s_{T L}^{2}}{s_{T L}^{2}-2 \rho s_{T L}^{2}+\rho s_{T H}^{2}+(1-\rho) \eta_{T} r \sigma^{2}}\right) \\
& =\frac{1}{2 \eta_{T}}\left(s_{T H}^{2}+s_{T L}^{2}-\frac{s_{T H}^{4}}{s_{T H}^{2}+\eta_{T} r \sigma^{2}}-\frac{(1-\rho) s_{T L}^{2}\left(s_{T L}^{2}-2 \rho s_{T L}^{2}+\rho s_{T H}^{2}\right)}{s_{T L}^{2}-2 \rho s_{T L}^{2}+\rho s_{T H}^{2}+(1-\rho) \eta_{T} r \sigma^{2}}\right)
\end{aligned}
$$


$(1 / 2) r \sigma^{2}\left(b_{L}^{S *}+b_{H}^{S *}\right)$ is about $r$ monotonically increasing.

Therefore, $G(r)$ is about $r$ monotonically decreasing, which maximizes $r \longrightarrow 0$ at and minimizes at $r \longrightarrow+\infty$.

$$
\begin{aligned}
G(+\infty) & =\left(\frac{s_{O}^{2}}{\eta_{O}}+\theta\right), \\
G(0) & =\left(\frac{s_{O}^{2}}{\eta_{O}}+\theta\right)+\frac{s_{T H}^{2}}{2 \eta_{T}}\left(1+\frac{(1-\rho) s_{T L}^{2}}{s_{T L}^{2}-2 \rho s_{T L}^{2}+\rho s_{T H}^{2}}\right) .
\end{aligned}
$$

Therefore, $G(r)>0$ and $a_{L}^{S^{*}} \geq a_{H}^{S^{*}}$, only when $r \longrightarrow+\infty$, $a_{L}^{S^{*}}=a_{H}^{S *}$.

Proof of Theorem A.3. (1)

$a_{H}^{S^{*}}-a_{L}^{S^{*}}=\left(1 / 2 \eta_{T}\right)\left(s_{T H}^{2}-s_{T L}^{2}\right)\left(b_{L}^{S^{*}}\right)^{2} \geq 0$;

(2) $b_{L}^{S^{*}}-b_{L}^{N^{*}}=\left(\rho s_{T L}^{2}\left(s_{T L}^{2}-s_{T H}^{2}\right) /\left(s_{T L}^{2}-2 \rho s_{T L}^{2}+\rho s_{T H}^{2}+\right.\right.$ $\left.\left.(1-\rho) \eta_{T} r \sigma^{2}\right)\left(s_{T L}^{2}+\eta_{T} r \sigma^{2}\right)\right) \leq 0$;

$$
a_{L}^{S^{*}}-a_{L}^{N^{*}}=\left(b_{L}^{N^{*}}-b_{L}^{S^{*}}\right)\left(\left(\frac{s_{O}^{2}}{\eta_{O}}+\theta\right)-\frac{1}{2}\left(r \sigma^{2}-\frac{s_{T L}^{2}}{\eta_{T}}\right)\left(b_{L}^{N^{*}}+b_{L}^{S^{*}}\right)\right) .
$$

The process of solving value of $\left(a_{L}^{S^{*}}-a_{L}^{N^{*}}\right)$ is similar to the proof of Corollary 1.

The proofs of (3) and (4) of theorem are easy, so they are omitted.

\section{Proof of Theorem A.4.}

(1) $\Delta E \Pi_{O H}^{S N^{*}}=E \Pi_{O H}^{S^{*}}-E \Pi_{O H}^{N^{*}}=\left(1 / 2 \eta_{T}\right)\left(s_{T L}^{2}-s_{T H}^{2}\right)$ $\left(b_{L}^{S^{*}}\right)^{2} \leq 0$

$$
\begin{aligned}
\Delta E \Pi_{O L}^{S N^{*}} & =E \Pi_{O L}^{S^{*}}-E \Pi_{O L}^{N^{*}}=\left(b_{L}^{S^{*}}-b_{L}^{N^{*}}\right)\left(\frac{s_{T L}^{2}}{\eta_{T}}-\frac{1}{2}\left(\frac{s_{T L}^{2}}{\eta_{T}}+r \sigma^{2}\right)\left(b_{L}^{N^{*}}+b_{L}^{S^{*}}\right)\right) \\
& =\frac{1}{\eta_{T}}\left(b_{L}^{S^{*}}-b_{L}^{N^{*}}\right)\left(s_{T L}^{2}-\frac{s_{T L}^{2}}{2 b_{L}^{N *}}\left(b_{L}^{N^{*}}+b_{L}^{S^{*}}\right)\right)=\frac{s_{T L}^{2}}{2 \eta_{T}}\left(b_{L}^{S^{*}}-b_{L}^{N^{*}}\right)\left(1-\frac{b_{L}^{S^{*}}}{b_{L}^{N^{*}}}\right) \\
& =-\frac{\left(s_{T L}^{2}+\eta_{T} r \sigma^{2}\right)}{2 \eta_{T}}\left(b_{L}^{S^{*}}-b_{L}^{N^{*}}\right)^{2} \leq 0 .
\end{aligned}
$$

(2) $\Delta E \Pi_{T H}^{S N^{*}}=E \Pi_{T H}^{S^{*}}-E \Pi_{T H}^{N^{*}}=\left(1 / 2 \eta_{T}\right)\left(s_{T H}^{2}-s_{T L}^{2}\right)$ $\left(b_{L}^{S^{*}}\right)^{2} \geq 0$

$$
\Delta E \Pi_{T H}^{S N^{*}}=E \Pi_{T L}^{S^{*}}-E \Pi_{T L}^{N^{*}}=0 .
$$

Proof of Theorem A.5. According to the display principle, when analyzing the validity of continuous variables, the analysis restriction can be displayed $\left\{a\left(\overleftrightarrow{s_{T}}\right), b\left(\overleftrightarrow{s_{T}}\right)\right\}$ directly. Therefore, $\forall\left(s_{T}, \overleftrightarrow{s_{T}}\right) \in H$, there is

$$
\begin{aligned}
& a^{C}\left(s_{T}\right)+\left(s_{O} e_{O}^{C}\left(s_{T}\right)+\theta\right) b^{C}\left(s_{T}\right)+\frac{1}{2}\left(\frac{s_{T}^{2}}{\eta_{T}}-r \sigma^{2}\right) b^{C 2}\left(s_{T}\right) \geq \\
& a^{C}\left(\overleftrightarrow{s_{T}}\right)+\left(s_{O} e_{O}^{C}\left(\overleftrightarrow{s_{T}}\right)+\theta\right) b^{C}\left(\overleftrightarrow{s_{T}}\right)+\frac{1}{2}\left(\frac{s_{T}^{2}}{\eta_{T}}-r \sigma^{2}\right) b^{C 2}\left(\overleftrightarrow{s_{T}}\right) .
\end{aligned}
$$


According to In equation (A.13), there is

$$
\begin{aligned}
& a^{C}\left(s_{T}\right)+\left(s_{O} e_{O}^{C}\left(s_{T}\right)+\theta\right) b^{C}\left(s_{T}\right)+\frac{1}{2}\left(\frac{s_{T}^{2}}{\eta_{T}}-r \sigma^{2}\right) b^{C 2}\left(s_{T}\right) \geq \\
& a^{C}\left(s_{T}^{\prime}\right)+\left(s_{O} e_{O}^{C}\left(s_{T}^{\prime}\right)+\theta\right) b^{C}\left(s_{T}^{\prime}\right)+\frac{1}{2}\left(\frac{s_{T}^{2}}{\eta_{T}}-r \sigma^{2}\right) b^{C 2}\left(s_{T}^{\prime}\right), \\
& a^{C}\left(s_{T}^{\prime}\right)+\left(s_{O} e_{O}^{C}\left(s_{T}^{\prime}\right)+\theta\right) b^{C}\left(s_{T}^{\prime}\right)+\frac{1}{2}\left(\frac{s_{T}^{\prime 2}}{\eta_{T}}-r \sigma^{2}\right) b^{C 2}\left(s_{T}^{\prime}\right) \geq \\
& a^{C}\left(s_{T}\right)+\left(s_{O} e_{O}^{C}\left(s_{T}\right)+\theta\right) b^{C}\left(s_{T}\right)+\frac{1}{2}\left(\frac{s_{T}^{\prime 2}}{\eta_{T}}-r \sigma^{2}\right) b^{C 2}\left(s_{T}\right) .
\end{aligned}
$$
as

In equations (A.14) and (A.15) are added and simplified

$$
\left(s_{T}-s_{T}^{\prime}\right)\left(b^{C}\left(s_{T}\right)-b^{C}\left(s_{T}^{\prime}\right)\right) \geq 0 .
$$

So $b^{C}\left(s_{T}\right)$ is no decreasing, which shows $b^{C}\left(s_{T}\right)$ is differentiable everywhere in the interval $\left[s_{T}, \overline{s_{T}}\right]$, and $b^{C}\left(s_{T}\right) \geq 0$. In addition, the first-order condition for $s_{T}$ is obtained $\quad a^{C}\left(\overleftrightarrow{s_{T}}\right)+s_{O} e_{O}^{C}\left(s_{T}\right) b^{C}\left(s_{T}\right)+\left(s_{O} e_{O}^{C}\left(s_{T}\right)+\theta\right) b^{C}$ $\left(s_{T}\right)+\left(\left(s_{T}^{2} / \eta_{T}\right)-r \sigma^{2}\right) b^{C}\left(s_{T}\right)=0$ from In equation (A.13).

According to the direct display mechanism, $\forall s_{T}^{C} \in H$ there is

$$
\begin{aligned}
& \dot{a} \dot{a}^{C}\left(s_{T}\right)+s_{O} e_{O}^{C}\left(s_{T}\right) b^{C}\left(s_{T}\right)+\left(s_{O} e_{O}^{C}\left(s_{T}\right)+\theta\right) \dot{b} \dot{b}^{C}\left(s_{T}\right) \\
& +\left(\frac{s_{T}^{2}}{\eta_{T}}-r \sigma^{2}\right) \dot{b}\left(s_{T}\right)=0 .
\end{aligned}
$$

In equations (18) and (19) are incentive compatibility constraints to ensure that the TTA has no motivation to deviate from the service reward contract provided by OTA. In equation (20) is the constraint condition for the TTA to participate in cooperation and cannot be lower than its reserved revenue.

Derivatives of equation (17), and further simplified according to equation (19)

$$
E \dot{\Pi}_{T}\left(s_{T}\right)=\frac{s_{T}}{\eta_{T}} b^{C 2}\left(s_{T}\right) .
$$

Bring $E \Pi_{T}\left(s_{T}\right)$ into equation (15), the above optimization problem P3 can be rewritten as follows $\mathrm{P} 3^{\prime}$

$$
\max _{a^{C}, b^{C}} \int_{\underline{s_{T}}}^{\overline{s_{T}}}\left\{s_{O} e_{O}^{C}\left(s_{T}\right)+\frac{s_{T}^{2} b^{C}\left(s_{T}\right)}{\eta_{T}}+\theta-\frac{1}{2}\left(\frac{s_{T}^{2}}{\eta_{T}}+r \sigma^{2}\right) b^{C 2}\left(s_{T}\right)-E \Pi_{T}\left(s_{T}\right)-\frac{\eta_{O} e_{O}^{C 2}\left(s_{T}\right)}{2}\right\} f\left(s_{T}\right) \mathrm{d} s_{T},
$$

s.t. in equation (18) and (A.18), $E \Pi_{T}\left(s_{T}\right) \geq \Pi_{T}$

Let $E \Pi_{T}\left(s_{T}\right) \geq \Pi_{T}$, the solution of integral equation (A.18) is obtained

$$
E \Pi_{T}\left(s_{T}\right)=\int_{\underline{s_{T}}}^{s_{T}} \frac{\omega}{\eta_{T}} b^{C 2}(\omega) \mathrm{d} \omega+\underline{\Pi_{T}} .
$$

According to. $\int_{s_{T}}^{\overline{s_{T}}}\left[\int_{s_{T}}^{s_{T}}\left(\omega / \eta_{T}\right) b^{C 2}(\omega) \mathrm{d} \omega\right] f\left(s_{T}\right) \mathrm{d} s_{T}=$ $\int_{\underline{s_{T}}}^{\overline{s_{T}}}\left[\int_{s_{T}}^{\overline{s_{T}}} f(\omega) \mathrm{d} \omega\right] \quad\left(\overline{s_{T} / \eta_{T}} \overline{)} \bar{b} C 2\left(s_{T}\right) \mathrm{d} s_{T}=\int_{\underline{s_{T}}}^{\overline{s_{T}}}\left(1-F\left(s_{T}\right) / f\right.\right.$ $\left.\left(\overline{s_{T}}\right)\right)\left(s_{T} / \eta_{T}\right) b^{C 2}\left(s_{T}\right) f\left(s_{T}\right) \mathrm{d} s_{T}$

Then the objective function of P3 is

$$
\max _{a^{C}, b^{C}} \int_{s_{T}}^{\overline{s_{T}}}\left\{s_{O} e_{O}^{C}\left(s_{T}\right)+\frac{s_{T}^{2} b^{C}\left(s_{T}\right)}{\eta_{T}}+\theta-\frac{1}{2}\left(\frac{s_{T}^{2}}{\eta_{T}}+r \sigma^{2}\right) b^{C 2}\left(s_{T}\right)-\frac{1-F\left(s_{T}\right)}{f\left(s_{T}\right)} \frac{s_{T}}{\eta_{T}} b^{C 2}\left(s_{T}\right)-\underline{\prod_{T}}-\frac{\eta_{O} e_{O}^{C 2}\left(s_{T}\right)}{2}\right\} f\left(s_{T}\right) \mathrm{d} s_{T} .
$$


The optimal solution is

$$
\begin{aligned}
e_{O}^{C *} & =\frac{s_{O}}{\eta_{O}}, \\
b^{C *}\left(s_{T}^{C}\right) & =\frac{1}{1+\left(\eta_{T} r \sigma^{2} / s_{T}^{C 2}\right)+\left(2\left(1-F\left(s_{T}^{C}\right)\right) / s_{T}^{C} f\left(s_{T}^{C}\right)\right)},
\end{aligned}
$$

Where, $\quad b^{C *}\left(\underline{s_{T}}\right)=\left(1 / 1+\left(\eta_{T} r \sigma^{2} / \underline{s_{T}}\right)+\left(2 / \underline{s_{T}} f\left(\underline{s_{T}}\right)\right)\right)$, $\left.b^{C *}\left(\overline{s_{T}}\right)=\left(1 / 1+\overline{(\eta}_{T} r \sigma^{2} /{\overline{s_{T}}}^{2}\right)\right)$

When $s_{T}=\underline{s_{T}}$, according to equation (16) and $E \Pi_{T}\left(\underline{s_{T}}\right)$ $=\Pi_{T}, a^{C *}\left(s_{T}\right) \overline{c a n}$ be obtained as

$$
a^{C *}\left(\underline{s_{T}}\right)=\underline{\Pi_{T}}-\left(\frac{s_{O}^{2}}{\eta_{O}}+\theta\right) b^{C *}\left(\underline{s_{T}}\right)-\frac{1}{2}\left(\frac{\underline{s}_{T}^{2}}{\overline{\eta_{T}}}-r \sigma^{2}\right) b^{C * 2}\left(\underline{s_{T}}\right) .
$$

Bring $b^{C *}\left(s_{T}^{C}\right)$ into equation (A.20), $E \Pi_{T}\left(s_{T}\right)$ can be obtained as

$$
E \Pi_{T}\left(s_{T}\right)=\int_{\underline{s_{T}}}^{s_{T}} \frac{\omega}{\eta_{T}} b^{C * 2}(\omega) \mathrm{d} \omega+\underline{\Pi_{T}} .
$$

Bring equation (A.24) into equation (17), $a^{C *}\left(s_{T}\right)$ can be obtained as

$$
\begin{aligned}
a^{C *}\left(s_{T}\right)= & \underline{\Pi_{T}}-\left(\frac{s_{O}^{2}}{\eta_{O}}+\theta\right) b^{C *}\left(s_{T}\right)-\frac{1}{2}\left(\frac{s_{T}^{2}}{\eta_{T}}-r \sigma^{2}\right) b^{C * 2}\left(s_{T}\right) \\
& +\int_{\underline{s_{T}}}^{s_{T}} \frac{\omega}{\eta_{T}} b^{C 2}(\omega) \mathrm{d} \omega .
\end{aligned}
$$

\section{Data Availability}

The data used to support the findings of this study are included within the article.

\section{Conflicts of Interest}

The authors declare that there are no conflicts of interest.

\section{Acknowledgments}

This work was supported by the Research Fund for the Scientific Research Foundation of Chongqing University of Technology and the Humanities and Social Sciences Research Project of Chongqing Education Commission (2020CJR06).

\section{References}

[1] L. Ling, X. Guo, and C. Yang, "Opening the online marketplace: an examination of hotel pricing and travel agency on-line distribution of rooms," Tourism Management, vol. 45, no. 1, pp. 234-243, 2014.

[2] E. H. C. Wu, R. Law, and B. Jiang, "Predicting browsers and purchasers of hotel websites," Cornell Hospitality Quarterly, vol. 54, no. 1, pp. 38-48, 2013.
[3] P. Shi and Y. Long, "A research on complementary resources input decision of the travel agencies co-creating the $\mathrm{O} 2 \mathrm{O}$ model," Tourism Science, vol. 31, no. 2, pp. 55-68, 2017.

[4] Y. Long and P. Shi, "Pricing strategies of tour operator and online travel agency based on cooperation to achieve $\mathrm{O} 2 \mathrm{O}$ model," Tourism Management, vol. 62, pp. 302-311, 2017.

[5] X. Guo, X. Zheng, L. Ling, and C. Yang, "Online coopetition between hotels and online travel agencies: from the perspective of cash back after stay," Tourism Management Perspectives, vol. 12, no. 12, pp. 104-112, 2014.

[6] P. Shi and Y. Long, "Service quality decision-making in $\mathrm{O} 2 \mathrm{O}$ tourism supply chains considering sharing service costs," Tourism Tribune, vol. 33, no. 11, pp. 90-100, 2018.

[7] C. Lu and S. Liu, "Cultural tourism O2O business model innovation-A case study of CTrip," Journal of Electronic Commerce in Organizations, vol. 14, no. 2, pp. 16-31, 2016.

[8] B. Koo, B. Mantin, and P. O'Connor, "Online distribution of airline tickets: should airlines adopt a single or a multichannel approach?" Tourism Management, vol. 32, no. 1, pp. 69-74, 2011.

[9] X. Guo, L. Ling, Y. Dong, and L. Liang, "Cooperation contract in tourism supply chains: the optimal pricing strategy of hotels for cooperative third party strategic websites," Annals of Tourism Research, vol. 41, pp. 20-41, 2013.

[10] Y. Dong and L. Ling, "Hotel overbooking and cooperation with third-party websites," Sustainability, vol. 7, no. 9, pp. 11696-11712, 2015.

[11] L. Xu, P. He, and Z. Hua, "A new form for a hotel to collaborate with a third-party website: setting online-exclusive-rooms," Asia Pacific Journal of Tourism Research, vol. 20, no. 6, pp. 1-12, 2014.

[12] D. Bell, S. Gallino, and A. Moreno, "Showrooms and information provision in omni-channel retail," Production and Operations Management, vol. 24, no. 3, pp. 360-362, 2015.

[13] I. D. Savila, R. N. Wathoni, and A. S. Santoso, "The role of multichannel integration, trust and offline-to-online customer loyalty towards repurchase intention: an empirical study in online-to-offline (O2O) e-commerce," Procedia Computer Science, vol. 161, pp. 859-866, 2019.

[14] B. Swoboda and A. Winters, "Effects of the most useful offlineonline and online-offline channel integration services for consumers," Decision Support Systems, vol. 145, Article ID 113522, 2021.

[15] L. Jin, X. Zhang, B. Dan, and S. Li, "Commission contract design in "offline evaluation, online purchase" (O2O) supply chain in the presence of cross-selling," Chinese Journal of Management Science, vol. 25, no. 11, pp. 33-46, 2017.

[16] J. K. Dong, W. G. Kim, and S. H. Jin, "A perceptual mapping of online travel agencies and preference attributes," Tourism Management, vol. 28, no. 2, pp. 591-603, 2007.

[17] A. H. Walle, "Tourism and the internet," Journal of Travel Research, vol. 35, no. 1, pp. 72-77, 1996.

[18] J. Xiao, B. Dan, and X. M. Zhang, "Service cooperation pricing strategy between manufactures and retailers in dual-channel supply chain," Systems Engineering-Theory \& Practice, vol. 30, no. 12, pp. 2203-2211, 2011.

[19] Q. Xu, G. Fu, and D. Fan, "Service sharing, profit mode and coordination mechanism in the Online-to-Offline retail market," Economic Modelling, vol. 91, pp. 659-669, 2020.

[20] Y.-W. Zhou, J. Guo, and W. Zhou, "Pricing/service strategies for a dual-channel supply chain with free riding and servicecost sharing," International Journal of Production Economics, vol. 196, pp. 198-210, 2018. 
[21] Q. Yang and M. Zhang, "Service cooperation incentive mechanism in a dual-channel supply chain under service differentiation," American Journal of Industrial and Business Management, vol. 05, no. 04, pp. 226-234, 2015.

[22] L. Zou, "Threat-based incentive mechanisms under moral hazard and adverse selection," Journal of Comparative Economics, vol. 16, no. 1, pp. 47-74, 1992.

[23] F. Chen, "Salesforce incentives, market information, and production/inventory planning," Management Science, vol. 51, no. 1, pp. 60-75, 2005.

[24] S.-H. Kim, M. A. Cohen, and S. Netessine, "Performance contracting in after-sales service supply chains," Management Science, vol. 53, no. 12, pp. 1843-1858, 2007.

[25] Y. He, X. Zhao, L. Zhao, and J. He, "Coordinating a supply chain with effort and price dependent stochastic demand," Applied Mathematical Modelling, vol. 33, no. 6, pp. 27772790, 2009.

[26] P. He, Y. He, C. Shi et al., "Cost-sharing contract design in a low-carbon service supply chain," Computers \& Industrial Engineering, vol. 139, Article ID 106160, 2020.

[27] J. Cao, C. J. Yang, P. Li, and G. Zhou, "Design of supply chain linear shared-saving contract with asymmetric information," Journal of Management Sciences in China, vol. 12, no. 2, pp. 19-30, 2009.

[28] Y. He, H. Huang, and D. Li, "Inventory and pricing decisions for a dual-channel supply chain with deteriorating products," Operational Research, vol. 20, no. 3, pp. 1461-1503, 2020.

[29] G. Xie, W. Yue, S. Wang, and K. K. Lai, "Quality investment and price decision in a risk-averse supply chain," European Journal of Operational Research, vol. 214, no. 2, pp. 403-410, 2011.

[30] Z. Li, S. M. Gilbert, and G. Lai, "Supplier encroachment under asymmetric information," Management Science, vol. 60, no. 2, pp. 449-462, 2013.

[31] Y. He, P. He, F. Xu, and C. Shi, "Sustainable tourism modeling: pricing decisions and evolutionarily stable strategies for competitive tour operators," Tourism Economics, vol. 25, no. 5, pp. 779-799, 2019.

[32] P. He, Y. He, and F. Xu, "Evolutionary analysis of sustainable tourism," Annals of Tourism Research, vol. 69, pp. 76-89, 2018. 